\title{
Exercise without dietary changes alleviates nonalcoholic fatty liver disease without weight loss benefits
}

\author{
Duck-Pil Ok, Kangeun Ko and Ju Yong Bae*
}

\begin{abstract}
Background: This study aimed to analyze the effect of exercise and/or dietary change on improvement of non-alcoholic fatty liver disease (NAFLD) in chronic high-fat diet (HFD)-induced obese mice.

Methods: Forty male C57BL/6 (8 weeks old) mice were divided into normal diet $(\mathrm{CO}, n=8)$ and high-fat diet $(H F, n=32)$ groups. The HF group was fed with $60 \%$ fat chow for 16 weeks to induce obesity. After the obesity induction period, the HF group was subdivided into HFD + sedentary $(n=8), H F D+$ training $(H F T, n=8)$, dietary change to normal-diet + sedentary (HFND, $n=8$ ), and dietary change to normal-diet + training (HFNDT, $n=8)$ groups, and the mice in the training groups underwent treadmill training for 8 weeks, 5 times per week, 40 min per day.

Results: A 24-week HFD induced increase of cannabinoid-1 receptor (CB1), fatty acid synthase (FAS), and AMP-activated protein kinase (AMPK) protein expressions $(p<0.05)$ and decrease of $p$-AMPK and carnitine palmitoyltransferase1 (CPT1) protein expressions $(P<0.05)$, resulting in increased liver fat accumulation. Treatment of exercise with dietary change and dietary change alone decreased CB1 and AMPK protein expressions with increased $\mathrm{p}$-AMPK and CPT1 protein expressions $(P<0.05)$, leading to decreased body weight and liver fat $(P<0.05)$. The CB1 and FAS protein expressions in the HFT group were still higher than those in the CO group $(P<0.05)$, but the $\mathrm{p}$-AMPK and CPT1 protein expressions were higher than those in the HF group $(P<0.05)$. Moreover, improved glucose tolerance and decreased liver fat were confirmed, although treatment of exercise alone had no effect on weight loss compared to pre-exercise.

Conclusions: Even in the case of obesity induced by chronic HFD, exercise and/or dietary interventions have preventive and therapeutic effects on fat accumulation in the liver, resulting from upregulations of lipolytic factors. Therefore, the results of this study suggested that treatment of exercise alone without dietary change also leads to improvement of NAFLD and glucose tolerance without weight loss benefits.
\end{abstract}

Keywords: NAFLD, Training, CB1 receptor, AMPK, FAS, CPT1

\section{Background}

Fatty liver disease is characterized by accumulation of lipids, mainly triglycerides, in hepatocytes in the absence of competing liver disease etiologies, which is an early stage of liver disease, such as alcoholic liver disease, non-alcoholic fatty liver disease (NAFLD), and hepatitis C [1]. Both pathological conditions, including central obesity, type 2 diabetes, dyslipidemia, hypertension, and

\footnotetext{
* Correspondence: kosa99@dau.ac.kr

Laboratory of Exercise Biochemistry, Department of Physical Education,

College of Arts and Physical Education, Dong-A University, 37

Nakdong-daero 550 beon-gil, Hadan-dong, Saha-gu, Busan 604-714, Republic of Korea
}

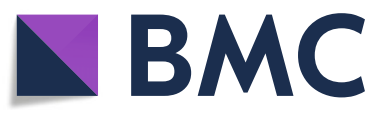

(๑) The Author(s). 2018 Open Access This article is distributed under the terms of the Creative Commons Attribution 4.0 International License (http://creativecommons.org/licenses/by/4.0/), which permits unrestricted use, distribution, and

reproduction in any medium, provided you give appropriate credit to the original author(s) and the source, provide a link to the Creative Commons license, and indicate if changes were made. The Creative Commons Public Domain Dedication waiver (http://creativecommons.org/publicdomain/zero/1.0/) applies to the data made available in this article, unless otherwise stated. high-fat diets, are risk factors for the development of NAFLD [2]. The overall global prevalence of NAFLD was estimated to be 25\%, and the prevalence of NAFLD in Asian populations is estimated to be $27 \%$ [3]. Because the prevalence of NAFLD is increasing worldwide and presents a public health burden, appropriate solutions are required for the alleviation of NAFLD.

Among the proposed mechanisms of NAFLD progression, lipogenic transcription factor activation [4] and impaired functions of lipolytic transcription factor [5] are directly related to the development of fatty liver. 
Cannabinoid-1 receptor (CB1), which responds to cannabinoids that increase fat intake, regulates the activity of these lipogenic and lipolytic transcription factors $[6,7]$, and the intake of ethanol and high-fat diet induce upregulation of $\mathrm{CB} 1$ activity through increased synthesis of endocannabinoids, 2-AG, and anandamide [1]. Because CB1 is also upregulated in obesity, CB1 is a potential therapeutic target for obesity and NAFLD [8].

The CB1 antagonist Rimonabant (Acomplia, Sanofi-Aventis) was initially developed for the treatment of obesity, and its effect was better than expected [9-11]. However, safety of Rimonabant was of concern because of the occurrence of central adverse effects, including nausea, anxiety, sleep disturbances, and depression, and clinical trials were eventually discontinued [12]. Although claims for drug development have been raised that $\mathrm{CB} 1$ antagonists should encourage ongoing efforts to develop peripherally restricted molecules that will prevent potential adverse central effects [8], there is no remarkable achievement to date.

Previous studies reported that a certain level of weight reduction is necessary to alleviate NAFLD [13, 14]. Exercise is one of the most effective ways to reduce body weight and fat accumulation by facilitating metabolic processes without any side effects. Dietary restriction or dietary conversion to low calories is also well known as an effective treatment for weight loss. Thus, regular exercise and dietary intervention have been recommended to alleviate NAFLD through weight reduction. A few studies examined the effects of exercise with dietary restriction on improvement of NAFLD, but the effect of the treatment of exercise alone that does not induce weight reduction is still unclear.

Therefore, the purpose of this study was to analyze the effect of exercise and/or dietary change on improvement of NAFLD in chronic high-fat diet (HFD) induced obese mice.

\section{Methods}

\section{Animals and maintenance}

Forty male C57BL/6 (8 weeks old) mice were used in this study. Four mice were housed per cage in the Dong-A University College of Medicine Animal Laboratory. The laboratory conditions were maintained constant: 55\% relative humidity, $22 \pm 2{ }^{\circ} \mathrm{C}$, and a 12-h dark-light cycle. The animal experiments were approved by the Dong-A University Medical School Institutional Animal Care and Use Committee (DIACUC-approval-16-17), and all procedures were performed in accordance with the committee guidelines.

\section{Obesity induction}

The animals were randomly divided into two groups to induce obesity: normal diet + sedentary group
(ND, $n=8)$ and HFD + sedentary group (HF, $n=32$ ). For 16 weeks, the HF group was fed with $60 \%$ fat chow (60\% lipid, $20 \%$ carbohydrate, and $20 \%$ protein) to induce obesity, whereas the $\mathrm{CO}$ group was fed with a standard chow (6.3\% lipid, 69.4\% carbohydrate, and $24.3 \%$ protein). Body weight was measured weekly during the entire experimental period.

\section{Exercise and dietary intervention}

After 16 weeks of obesity induction, the mice in the HF group were randomly subdivided into $\operatorname{HF}(n=8)$, HFD + training (HFT, $n=8$ ), dietary change to normal diet + sedentary (HFND, $n=8$ ), and dietary change to normal diet + training (HFNDT, $n=8$ ) groups. Animals in the HFT and HFNDT groups underwent exercise training on an animal treadmill five times per week for eight weeks. The exercise intensity was adjusted to $5 \mathrm{~m} / \mathrm{min}$ for $5 \mathrm{~min}, 12 \mathrm{~m} / \mathrm{min}$ for $30 \mathrm{~min}$, and $5 \mathrm{~m} / \mathrm{min}$ for $5 \mathrm{~min}$, at $0 \%$ slope for the first four weeks of training. The intensity of exercise was increased to $5 \mathrm{~m} / \mathrm{min}$ for $5 \mathrm{~min}, 14 \mathrm{~m} / \mathrm{min}$ for $30 \mathrm{~min}$, and $5 \mathrm{~m} / \mathrm{min}$ for $5 \mathrm{~min}$, also at $0 \%$ slope for the last four weeks of training [15].

\section{Glucose tolerance test}

As previously described [16], an intraperitoneal glucose tolerance test (GTT) was performed after a 16-h overnight fast. Plasma glucose concentrations were measured in tail blood using a GlucoDr Blood Glucose Test Strip (Allmedicus, Anyang, South Korea) before and 30, 60, 90, and $120 \mathrm{~min}$ after intraperitoneally injecting a bolus of glucose $(1 \mathrm{mg} / \mathrm{g})$ for the GTT.

\section{Tissue sampling}

Tissue sampling was conducted $48 \mathrm{~h}$ after the completion of the last exercise to prevent temporary training effects. Food was removed from the mouse cages $12 \mathrm{~h}$ before the mice were sacrificed. Liver tissues were excised after complete anesthesia (ethyl ether), and extracted samples were immediately weighed, frozen in liquid nitrogen, and stored at $-80{ }^{\circ} \mathrm{C}$.

\section{Hematoxylin and eosin staining}

Small pieces of liver tissue were fixed with formalin (10\% neutral-buffer formalin) and embedded in paraffin. Five-micrometer sections were cut and stained using hematoxylin and eosin (H\&E). Digital images of the slides were captured with an Aperio ScanScope (Aperio, USA).

\section{Extraction of liver triglycerides}

Liver samples were weighted $(50 \mathrm{mg})$, and $200 \mu \mathrm{l}$ of ethanolic $\mathrm{KOH}$ ( 2 parts ethanol: 1 part $30 \% \mathrm{KOH}$ ) was added to each sample and incubated overnight at $55{ }^{\circ} \mathrm{C}$. 
Subsequently, it was mixed with $50 \%$ ethanol into each tube to bring the volume to $0.5 \mathrm{ml}$ and centrifuged for $5 \mathrm{~min}$ at 13,000 rpm. The supernatant was transferred into new tubes, and 50\% ethanol was added again into each tube to bring the volume to $0.6 \mathrm{ml}$. After vortexing, $200 \mu \mathrm{l}$ was moved to a new tube, and $215 \mu \mathrm{l}$ of $1 \mathrm{M}$ $\mathrm{MgCl}_{2}$ was added, incubated for $10 \mathrm{~min}$ on ice, and centrifuged for $5 \mathrm{~min}$ at 13,000 rpm. The supernatant was used to measure liver TG using ASAN set Triglyceride-S Reagent (Asan Pharmaceutical, Seoul, South Korea) by the enzymatic colorimetric method. Liver lysates and standards were added into the microplate and incubated at $37{ }^{\circ} \mathrm{C}$ for $10 \mathrm{~min}$. Absorbance values were measured at $550 \mathrm{~nm}$.

\section{Western blotting}

As previously described [15], the liver tissues were lysed in $200 \mu \mathrm{l}$ radioimmunoprecipitation assay (RIPA) buffer to extract protein from the samples. The tissue was homogenized and centrifuged for $30 \mathrm{~min}$ at 14,000 rpm. The protein concentration of the supernatant was measured using the BCA protein assay kit (PIERCE, USA). Samples of equal protein content were resolved by SDS-polyacrylamide gel electrophoresis on a 10 or $12 \%$ gel and transferred to a membrane. The membrane was blocked with $5 \%$ skim milk in phosphate-buffered saline (PBS), and subsequently incubated at $4{ }^{\circ} \mathrm{C}$ overnight with primary antibodies (1:1000 dilution) against CB1 (sc-293419), fatty acid synthase (FAS, sc-74540), carnitine palmitoyltransferase1 (CPT1, sc-393070) (all from Santa Cruz Biotechnology, USA), AMP-activated protein kinase (AMPK, \#2532, Cell Signaling Technology, USA), and phosphor-AMPK (p-AMPK, \#2531, Cell Signaling Technology). The membrane was incubated with goat anti-mouse or anti-rabbit IgG conjugated secondary antibody for $1 \mathrm{~h}$ at room temperature. The signal was developed with an ECL solution (Amersham Pharmacia Biotech, USA) and visualized with ImageQuantTM LAS-4000 system (GE Healthcare, Sweden).

\section{Statistical analysis}

All statistical analyses were performed with Statistical Package for Social Sciences (version 22.0); values were presented as means \pm SE. To compare groups, we performed analysis of variance, using the least-square difference post hoc test to validate significant differences. A significance level of $p=0.05$ was used as a threshold for statistical significance.

\section{Results}

Chronic HFD induced obesity, glucose tolerance, and fat accumulation in liver

Body weight in the HF group was significantly higher than that in the CO group after 16 weeks of HFD $(p<0.001)$; thus, we determined that obesity was induced in the HF group (Fig. 1a). Body weight in the HF group was significantly higher than that in all other groups after eight weeks of exercise and/or dietary intervention $(p<0.05)$ (Fig. 1b), and the blood glucose level in the HF group tended to increase over time (Fig. 2). Furthermore, chronic HFD increased liver weight (Fig. 3c) and liver TG (Fig. 3d) $(p<0.05)$.

\section{Both exercise and/or dietary intervention alleviates body} weight gain, glucose tolerance, and fat accumulation in liver Eight weeks of regular exercise and/or dietary conversion showed improvement in obesity caused by chronic HFD. The body weight in the HFT, HFND, and HFNDT groups was significantly lower than that in the HF group $(p<0.05)$ (Fig. 1b). Dietary change groups achieved weight loss effects regardless of whether exercise was conducted. The body weight in the HFT group did not decrease, but the prophylactic effect of weight gain was observed.

The blood glucose levels in the HF and HFT groups were significantly higher than those in the HFND and HFNDT groups during most periods of GTT $(p<0.05)$. However, blood glucose in the HFT group tended to decrease over time, suggesting that exercise without dietary conversion is somewhat effective in blood glucose control (Fig. 2). Therefore, dietary conversion is considered to be essential for gaining the maximum benefit from blood glucose control.

Eight weeks of exercise and/or dietary intervention induced significant decrease of liver weight (Fig. 3c) and liver TG (Fig. 3d) in both training and/or dietary change groups $(p<0.05)$.

\section{Both exercise and/or dietary intervention alleviates fatty liver by regulation of protein expressions related fat accumulation in liver}

Protein expression related to fat accumulation in the liver after eight weeks of training are presented in Fig. 4. The protein expression of CB1, FAS, and AMPK was significantly higher, and CPT1 and p-AMPK were significantly lower in the HF group than those in the $\mathrm{CO}$ group $(p<0.05)$. Although the protein expression of CB1 and FAS in the HFT group was not significantly different from that in the HF group, the protein expression of CPT1, p-AMPK, and AMPK in the HFT group was significantly higher than those in the HF group $(p<0.05)$. In the protein expression of the HFND group, CB1 and AMPK were significantly lower, and CPT1 was significantly higher than those in the HF group $(p<0.05)$. In the protein expression of the HFNDT group, CB1 and AMPK were significantly lower, and CPT1 and p-AMPK were significantly higher than those in the HF group $(p<0.05)$. 
A

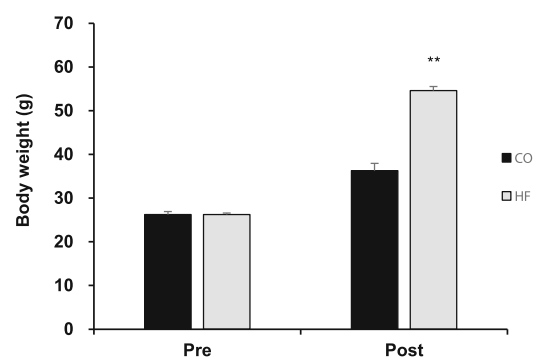

B

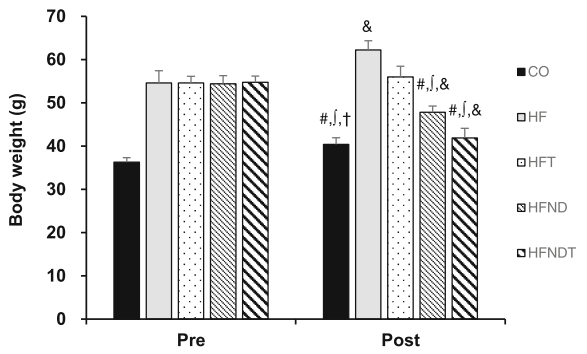

Fig. 1 Changes in body weight after intervention. Changes in body weight after 16-week HFD (a) and 8-week training and/or dietary change (b). Data are expressed as mean \pm SE. CO, normal-diet group; HF, high-fat diet group; HFT, high-fat diet + training group; HFND, dietary change to a normal diet group; HFNDT, dietary change to a normal diet + training group. ${ }^{* *}$ versus CO group, $p<0.001$; ${ }^{*}$ versus HF group, $p<0.05 ;{ }^{\zeta}$ versus HFT group, $p<0.05 ;^{\dagger}$ versus HFND group, $p<0.05 ;^{\&}$ versus before, $p<0.05$

\section{Discussion}

In this study, we confirmed that CB1 and FAS protein expressions were increased in liver tissue of chronic HFD mice, and AMPK and CPT1 protein expressions were decreased. After combination of regular exercise and dietary change intervention, however, fat synthesis decreased and beta oxidation of fatty acids increased. Moreover, treatment of exercise alone also induced improvement of liver weight, liver TG with beta oxidation of fatty acids increased without benefits of weight loss.

The overall prevalence of NAFLD worldwide and in Asian populations was estimated to be $>25 \%$ [3] and has also sharply increased over the past several decades in Korean populations [17]. The progression of NAFLD is usually slow over and more a decade, and it is asymptomatic in most cases [18], and $10-20 \%$ of NAFLD patients eventually progress to not only non-alcoholic steatohepatitis, but also multi-organ systemic diseases [17].

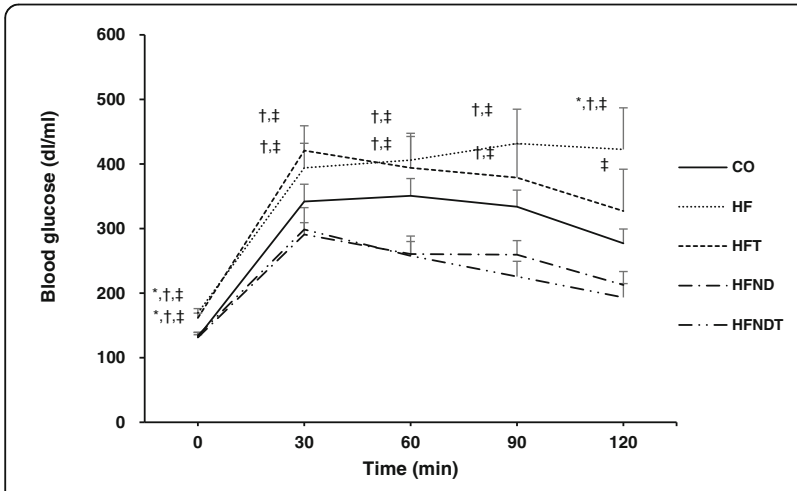

Fig. 2 Glucose tolerance test after 8-week training and/or dietary change. Changes in blood glucose after 8-week intervention. Data are expressed as mean $\pm \mathrm{SE}$. CO, normal-diet group; $\mathrm{HF}$, high-fat diet group; HFT, high-fat diet + training group; HFND, dietary change to a normal diet group; HFNDT, dietary change to a normal diet + training group. ${ }^{*}$ versus CO group, $p<0.05 ;{ }^{\dagger}$ versus HFND group, $p<0.05 ;{ }^{\ddagger}$ versus HFNDT group, $p<0.05$
Excess fat accumulation in liver could result from (a) increased de novo fatty acid synthesis, (b) increased transport of fatty acids from the other organs to the liver, (c) decreased fatty acid oxidation, and (d) decreased transport of triglycerides from the liver to other organs [1]. In this respect, exceed lipid in the body due to HFD could directly or indirectly promotes fat accumulation in the liver. Evidence showing that the increase of lipogenic factors and decrease of lipolytic factors induced fat accumulation in the liver was well known, through both human $[19,20]$ and animal studies $[21,22]$. In this study, as expected, chronic HFD increased lipogenic factor, such as FAS with decreased lipolytic factors, such as AMPK and CPT1, which induced increased fat accumulation, size, and liver weight.

Emerging evidence suggests that cannabinoids play an important role in the regulation of fatty liver $[1,8,23]$. The main endocannabinoids (endogenous cannabinoids) discovered are anandamide and 2-arachidonoylglycerol, and its receptors have been identified are CB1 and cannabinoid receptor 2 [1]. A previous study reported that an HFD increases hepatic levels of anandamide, CB1 protein level, and basal rates of fatty acid synthesis, and the latter is reduced by CB1 blockade [24]. The mechanism underlying these effects is that hepatocytes express CB1, stimulation that induces the increase of de novo fatty acid synthesis resulting from the expressions of SREBP-1c and its target enzymes [24, 25]. Furthermore, researchers have reported that CB1 knockout mice were totally resistant to HFD-induced obesity and steatosis [26-28]. These studies clearly support the important role of CB1 receptors in HFD-induced fatty liver and obesity. In this study, 16 weeks of HFD induced increase of FAS protein expression, which acts as a lipogenic factor, and decrease of lipolytic factors, such as AMPK and CPT1 through upregulation of CB1, resulting in accumulation of liver fat. However, although CB1 protein expression was upregulated by chronic HFD, treatment of exercise alone without 

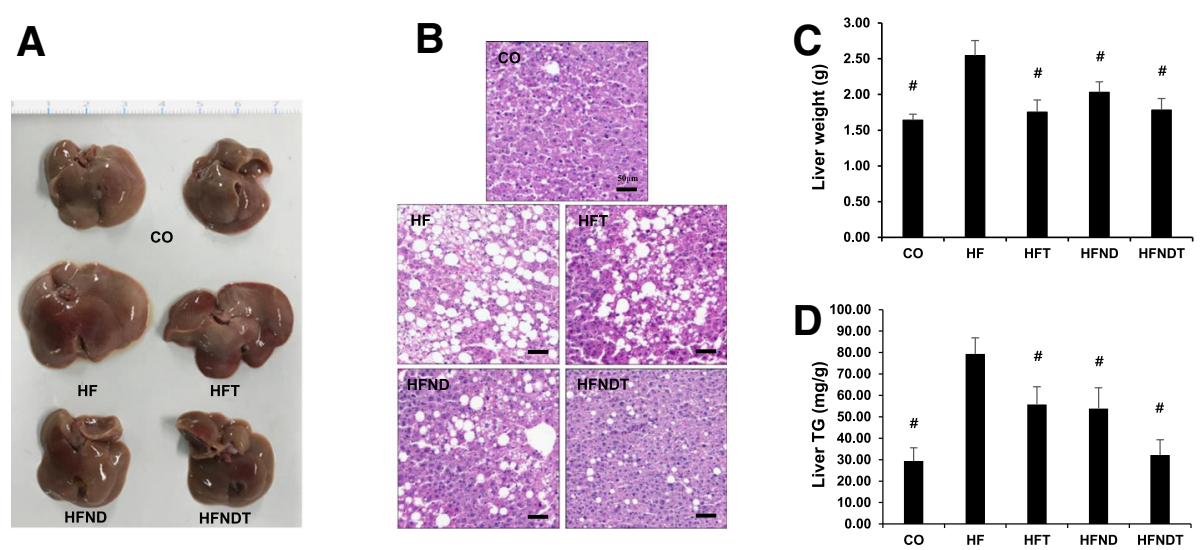

Fig. 3 Changes of liver after 8-week training and/or dietary change. Changes in liver size (a), lipid droplet (b), liver weight (c), and liver triglyceride (d) after treadmill training. Data are expressed as mean \pm SE. CO, normal-diet group; HF, high-fat diet group; HFT, high-fat diet + training group; HFND, dietary change to a normal diet + sedentary group; HFNDT, dietary change to a normal diet + training group. ${ }^{\#}$ versus $\mathrm{HF}$ group, $p<0.05$. Scale bar $=50 \mu \mathrm{m}$

dietary change upregulated lipolytic factors and inhibited liver fat accumulation.

The high prevalence of NAFLD had provided a challenge for many researchers, resulting in the conducting of studies on treatment strategies for NAFLD [29-32]. Because NAFLD patients are usually obese and have insulin resistance, lifestyle modification and pharmacologic therapies to regulate the body weight and related target enzymes and hormones have been proposed as treatment for NAFLD. Body weight loss of at least 3\% to $5 \%$ is required to reduce liver steatosis $[13,14]$, for this reason, lifestyle modification for weight loss, such as exercise and/or dietary change intervention, is recommended as the first intervention of NAFLD. Kenneally et al. (2017) conducted a study of efficacy of dietary and physical activity intervention in NAFLD, suggesting that combination of moderate dietary restriction and 30-60 min of moderate-intensity exercise was effective in reducing NAFLD activity. In trials evaluating dietary modification or exercise intervention alone, dietary intervention alone was enough to reduce body weight, whereas exercise intervention alone was not [32]. Nevertheless, exercise trials lead to an improvement in NAFLD by significantly reducing one or more markers of NAFLD without weight loss [33-35]. This study also showed that combined treatment and dietary change treatment alone were effective in improving fatty liver through inhibition of CB1. Particularly, it is noteworthy that improvement of glucose tolerance and
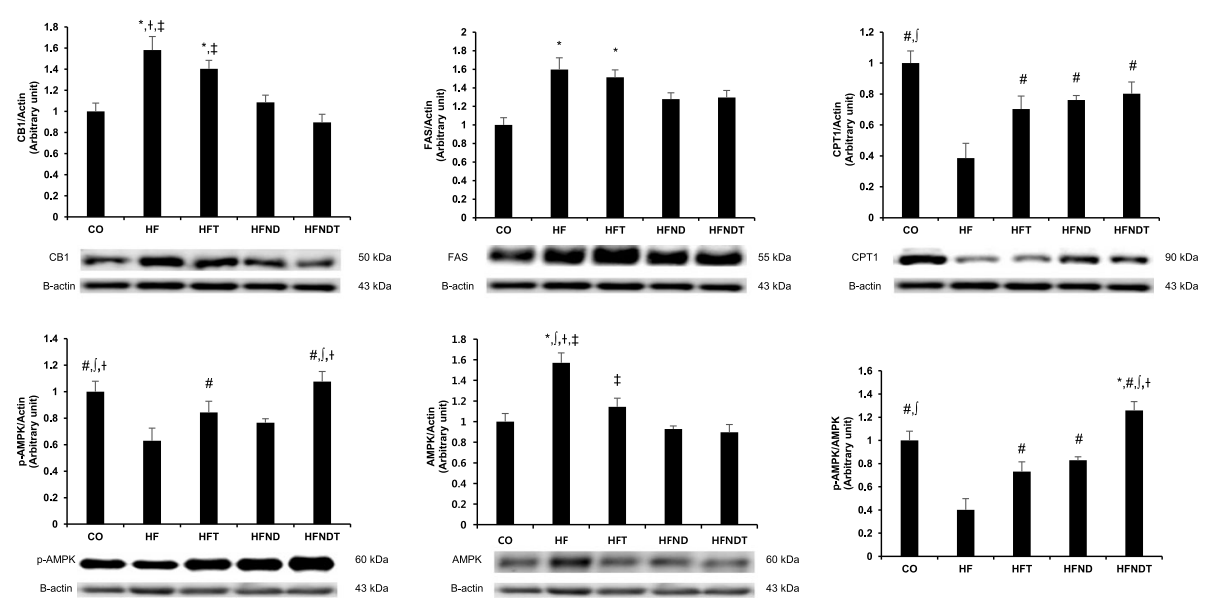

Fig. 4 Protein expressions in the liver after 8-week training and/or dietary change. Protein expressions in the liver after 8-week intervention. Data are expressed as mean \pm SE. CO, normal-diet group; HF, high-fat diet group; HFT, high-fat diet + training group; HFND, dietary change to a normal diet group; HFNDT, dietary change to a normal diet + training group. * versus CO group, $p<0.05$; ${ }^{\#}$ versus HF group, $p<0.05$; versus HFT group, $p<0.05 ;{ }^{\dagger}$ versus HFND group, $p<0.05 ;{ }^{*}$ versus HFNDT group, $p<0.05$ 
decreased liver TG were observed, although exercise intervention alone had no effect on weight loss compared with pre-exercise. In our previous study, regular exercise alone did not reduce body weight but improved insulin resistance [36]. In fact, observing the effects of regular exercise on weight loss during the growing period when the body weight gradually increases is difficult. Therefore, for improving NAFLD, associating not only body weight reduction but also changes in body composition, such as body mass, muscle mass, and fat mass may be necessary.

\section{Conclusion}

Even in the case of obesity induced by chronic HFD, exercise and/or dietary intervention had preventive and therapeutic effects on fat accumulation in the liver, resulting from upregulations of lipolytic factors. Therefore, the results of this study suggested that treatment of exercise alone without dietary change also led to improvement of NAFLD and glucose tolerance without benefits of weight loss.

\section{Abbreviations}

NAFLD: Non-alcoholic fatty liver disease; HFD: High-fat diet;

CB1: Cannabinoid 1 receptor; AMPK: AMP-activated protein kinase; FAS: Fatty acid synthase; CPT1: Carnitine palmitoyltransferase1

\section{Acknowledgements}

We thank all of the participants for their contribution to this study.

\section{Funding}

This work was supported by the Dong-A University research fund.

\section{Availability of data and materials}

The datasets analyzed during the current study are available from the corresponding author on reasonable request.

\section{Authors' contributions}

DPO and JYB took part in study design and writing the manuscript. All authors conducted animal experiments and analyzed the data. All authors also read and approved the final version of this manuscript.

\section{Ethics approval}

These animal experiments were approved by the Dong-A University Medical School Institutional Animal Care and Use Committee (DIACUC-approval-16-17).

\section{Consent for publication}

Not applicable.

Competing interests

The authors declare that they have no competing interests.

\section{Publisher's Note}

Springer Nature remains neutral with regard to jurisdictional claims in published maps and institutional affiliations.
Received: 10 July 2018 Accepted: 23 August 2018

Published online: 01 September 2018

\section{References}

1. Purohit V, Rapaka R, Shurtleff D. Role of cannabinoids in the development of fatty liver (steatosis). AAPS J. 2010;12(2):233-7.

2. Souza MR, Diniz Mde F, Medeiros-Filho JE, Araujo MS. Metabolic syndrome and risk factors for non-alcoholic fatty liver disease. Arq Gastroenterol. 2012:49(1):89-96.

3. Younossi ZM, Koenig AB, Abdelatif D, Fazel Y, Henry L, Wymer M. Global epidemiology of nonalcoholic fatty liver disease-meta-analytic assessment of prevalence, incidence, and outcomes. Hepatology. 2016;64(1):73-84.

4. You M, Crabb DW. Molecular mechanisms of alcoholic fatty liver: role of sterol regulatory element-binding proteins. Alcohol. 2004;34(1):39-43.

5. Fischer M, You M, Matsumoto M, Crabb DW. Peroxisome proliferatoractivated receptor alpha (PPARalpha) agonist treatment reverses PPARalpha dysfunction and abnormalities in hepatic lipid metabolism in ethanol-fed mice. J Biol Chem. 2003;278(30):27997-004.

6. Regnell SE. Cannabinoid 1 receptor in fatty liver. Hepatol Res. 2013;43(2): $131-8$.

7. Jeong WI, Osei-Hyiaman D, Park O, Liu J, Batkai S, Mukhopadhyay P, Horiguchi N, Harvey-White J, Marsicano G, Lutz B, Gao B, Kunos G. Paracrine activation of hepatic CB1 receptors by stellate cell-derived endocannabinoids mediates alcoholic fatty liver. Cell Metab. 2008;7(3):227-35.

8. Mallat A, Lotersztain S. Cannabinoid receptors as novel therapeutic targets for the management of non-alcoholic steatohepatitis. Diabetes Metab. 2008;34(6 Pt 2):680-4.

9. Despres JP, Golay A, Sjostrom L. Rimonabant in obesity-lipids study group. Effects of rimonabant on metabolic risk factors in overweight patients with dyslipidemia. N Engl J Med. 2005;353(20):2121-34.

10. Pi-Sunyer FX, Aronne L, Heshmati HM, Devin J, Rosenstock J. RIO-North America study group. Effect of rimonabant, a cannabinoid-1 receptor blocker, on weight and cardiometabolic risk factors in overweight or obese patients: RIO-North America: a randomized controlled trial. JAMA. 2006; 295(7):761-75

11. Van Gaal LF, Scheen AJ, Rissanen AM, Rossner S, Hanotin C, Ziegler O, RIOEurope Study Group. Long-term effect of CB1 blockade with rimonabant on cardiometabolic risk factors: two year results from the RIO-Europe study. Eur Heart J 2008;29(14):1761-1771.

12. Janero DR, Makriyannis A. Cannabinoid receptor antagonists: pharmacological opportunities, clinical experience, and translational prognosis. Expert Opin Emerg Drugs. 2009;14(1):43-65

13. Patel NS, Doycheva I, Peterson MR, Hooker J, Kisselva T, Schnabl B, Seki E, Sirlin CB, Loomba R. Effect of weight loss on magnetic resonance imaging estimation of liver fat and volume in patients with nonalcoholic steatohepatitis. Clin Gastroenterol Hepatol. 2015;13(3):561-8.

14. Wong WW, Chan RS, Wong GL, Cheung BH, Chu WC, Yeung DK, Chim AM, Lai JW, Li LS, Sea MM, Chan FK, Sung JJ, Woo J, Chan HL. Community-based lifestyle modification programme for non-alcoholic fatty liver disease: a randomized controlled trial. J Hepatol. 2013;59(3):536-42.

15. Bae JY, Woo J, Roh HT, Lee YH, Ko K, Kang S, Shin KO. The effects of detraining and training on adipose tissue lipid droplet in obese mice after chronic high-fat diet. Lipids Health Dis. 2017;16(1):13-016-0398-X.

16. Kim HY, Kwon WY, Kim YA, Oh YJ, Yoo SH, Lee MH, Bae JY, Kim JM, Yoo YH. Polychlorinated biphenyls exposure-induced insulin resistance is mediated by lipid droplet enlargement through Fsp27. Arch Toxicol. 2017:91(6):2353-63.

17. Kim W. Treatment options in non-alcoholic fatty liver disease. Korean J Gastroenterol. 2017:69(6):353-8

18. Metrakos P, Nilsson T. Non-alcoholic fatty liver disease-a chronic disease of the 21(st) century. J Biomed Res. 2017:0(0):1-9.

19. Yang ZX, Sun $H$, Shen W. Expression and action of hepatic sterol regulatory element-binding protein-1c in patients with nonalcoholic fatty liver disease. Zhonghua Gan Zang Bing Za Zhi. 2008;16(11):823-6.

20. Kohjima M, Higuchi N, Kato M, Kotoh K, Yoshimoto T, Fujino T, Yada M, Yada R, Harada N, Enjoji M, Takayanagi R, Nakamuta M. SREBP-1c, regulated by the insulin and AMPK signaling pathways, plays a role in nonalcoholic fatty liver disease. Int J Mol Med. 2008:21(4):507-11.

21. Peng CH, Yang MY, Yang YS, Yu CC, Wang CJ. Antrodia cinnamomea prevents obesity, dyslipidemia, and the derived fatty liver via regulating AMPK and SREBP signaling. Am J Chin Med. 2017;45(1):67-83. 
22. Frederico MJ, Vitto MF, Cesconetto PA, Engelmann J, De Souza DR, Luz G, Pinho RA, Ropelle ER, Cintra DE, De Souza CT. Short-term inhibition of SREBP-1C expression reverses diet-induced non-alcoholic fatty liver disease in mice. Scand J Gastroenterol. 2011:46(11):1381-8.

23. Alswat KA. The role of endocannabinoids system in fatty liver disease and therapeutic potentials. Saudi J Gastroenterol. 2013;19(4):144-51.

24. Osei-Hyiaman D, DePetrillo M, Pacher P, Liu J, Radaeva S, Batkai S, HarveyWhite J, Mackie K, Offertaler L, Wang L, Kunos G. Endocannabinoid activation at hepatic $C B 1$ receptors stimulates fatty acid synthesis and contributes to diet-induced obesity. J Clin Invest. 2005;115(5):1298-305.

25. Jourdan T, Djaouti L, Demizieux L, Gresti J, Verges B, Degrace P. CB1 antagonism exerts specific molecular effects on visceral and subcutaneous fat and reverses liver steatosis in diet-induced obese mice. Diabetes. 2010;59(4):926-34

26. Osei-Hyiaman D, Liu J, Zhou L, Godlewski G, Harvey-White J, Jeong WI, Batkai S, Marsicano G, Lutz B, Buettner C, Kunos G. Hepatic CB1 receptor is required for development of diet-induced steatosis, dyslipidemia, and insulin and leptin resistance in mice. J Clin Invest. 2008;118(9):3160-9.

27. Gary-Bobo M, Elachouri G, Gallas JF, Janiak P, Marini P, Ravinet-Trillou C, Chabbert M, Cruccioli N, Pfersdorff C, Roque C, Arnone M, Croci T, Soubrie P, Oury-Donat F, Maffrand JP, Scatton B, Lacheretz F, Le Fur G, Herbert JM, Bensaid M. Rimonabant reduces obesity-associated hepatic steatosis and features of metabolic syndrome in obese Zucker fa/fa rats. Hepatology. 2007:46(1):122-9.

28. Ravinet Trillou C, Delgorge C, Menet C, Arnone M, Soubrie P. CB1 cannabinoid receptor knockout in mice leads to leanness, resistance to dietinduced obesity and enhanced leptin sensitivity. Int J Obes Relat Metab Disord 2004;28(4):640-648

29. Golabi P, Bush H, Younossi ZM. Treatment strategies for nonalcoholic fatty liver disease and nonalcoholic steatohepatitis. Clin Liver Dis. 2017;21(4):739-53.

30. Singh S, Osna NA, Kharbanda KK. Treatment options for alcoholic and non-alcoholic fatty liver disease: a review. World J Gastroenterol. 2017;23(36):6549-70

31. Hung CK. Bodenheimer HC,Jr. current treatment of nonalcoholic fatty liver disease/nonalcoholic steatohepatitis. Clin Liver Dis. 2018;22(1):175-87.

32. Kenneally S, Sier JH, Moore JB. Efficacy of dietary and physical activity intervention in non-alcoholic fatty liver disease: a systematic review. BMJ Open Gastroenterol. 2017;4(1):e000139.

33. Johnson NA, Sachinwalla T, Walton DW, Smith K, Armstrong A, Thompson MW, George J. Aerobic exercise training reduces hepatic and visceral lipids in obese individuals without weight loss. Hepatology. 2009;50(4):1105-12.

34. Sullivan S, Kirk EP, Mittendorfer B, Patterson BW, Klein S. Randomized trial of exercise effect on intrahepatic triglyceride content and lipid kinetics in nonalcoholic fatty liver disease. Hepatology. 2012;55(6):1738-45.

35. Takahashi A, Abe K, Usami K, Imaizumi H, Hayashi M, Okai K, Kanno Y, Tanji $\mathrm{N}$, Watanabe $\mathrm{H}$, Ohira $\mathrm{H}$. Simple resistance exercise helps patients with non-alcoholic fatty liver disease. Int J Sports Med. 2015;36(10):848-52.

36. Bae JY, Shin KO, Woo J, Woo SH, Jang KS, Lee YH, Kang S. Exercise and dietary change ameliorate high fat diet induced obesity and insulin resistance via mTOR signaling pathway. J Exerc Nutrition Biochem. 2016;20(2):28-33.

Ready to submit your research? Choose BMC and benefit from:

- fast, convenient online submission

- thorough peer review by experienced researchers in your field

- rapid publication on acceptance

- support for research data, including large and complex data types

- gold Open Access which fosters wider collaboration and increased citations

- maximum visibility for your research: over $100 \mathrm{M}$ website views per year

At $\mathrm{BMC}$, research is always in progress.

Learn more biomedcentral.com/submissions 